\title{
Turning the Tables on McTaggart ${ }^{1}$
}

\author{
EMILIANO BOCCARDI
}

\begin{abstract}
According to A-theories of time, the metaphysical ground of change and dynamicity is provided by a continuous shifting in which events are past, present and future (A-determinations). It is often claimed that these theories make better sense of our experience of dynamicity than their rival, the B-theories; according to the latter, dynamicity is grounded solely in the irreducible earlier-than relations (B-relations) which obtain between events or states of affairs. In this paper, I argue that the experience of time's dynamicity, on the contrary, cannot be accounted for solely in terms of representations of irreducible A-determinations, because any representation which is adequate to ground these experiences must itself involve representation of irreducible B-relations, while it needs not involve representation of A-determinations. Even if, as a matter of contingent fact, our experiences of dynamicity consisted of representations of successions of A-determinations, what would account for them being experiences of dynamicity would be solely the B-theoretic relations of succession, rather than the irrelevant A-theoretic nature of the relata.
\end{abstract}

\section{Introduction}

Let me begin with some stage setting. For the purposes of this paper, I take the B-theory to be the view that temporal reality comprises solely B-relations of (temporal) precedence, succession and simultaneity. A-determinations of pastness, presentness and futurity are taken to be unreal and illusory. According to the B-theory, objective A-determinations are totally absent from reality, even from that part of reality which consists of experiential events. It is important to stress that I take the B-relations in question to be irreducibly temporal, intrinsically oriented, genuinely dynamic relations (of the kind Oaklander calls 'R-relations', and Savitt 'absolute becoming'). ${ }^{2}$

1 Research for this paper was supported by grant 2015/20138-2 from FAPESP (Brazil). I wish to thank Nathan Oaklander, Federico Perelda and an anonymous referee for their insightful comments on earlier drafts of this paper.

2 Cf. N. Oaklander, 'The A-, B- and R-theories of Time: A Debate' in The Future of the Philosophy of Time (ed.) A. Bardon (New York: Routledge, 2012), 1-24; and S. Savitt, 'On Absolute Becoming and the Myth of Passage', in Time, Reality $\xi^{\circ}$ Experience (ed.) C. Callender (2002), 153-67. 


\section{Emiliano Boccardi}

A-theories, by contrast, are characterized by the claim that A-theoretic distinctions reflect objective distinctions. B-relations, according to this view, need not be absent from reality, or conceptually dependent on the instantiation of A-determinations (although this is probably the majority view). What is necessary to qualify a view as A-theoretic is that (i) A-determinations be not conceptually dependent on B-relations and that (ii) change, dynamicity, and the passage of time be uniquely accountable for in A-theoretic terms.

The main dispute in the philosophy of time has been largely concerned with the need to resolve a conflict between reasons of experience in favor of temporal passage and reasons of the intellect against it. The latter appeal to logic, to a priori principles, or to science, while the former typically make a direct appeal to experience.

The A-theories have been claimed to be better suited to do justice to how temporal reality seems to be. Some B-theorists conceded that reality appears dynamic but, convinced by intellectualistic reasons, concluded that these experiences must be illusory; ${ }^{3}$ others tried to show that the B-theory is equally capable of accounting for our experience of time's passage. ${ }^{4}$ Very few, however, have argued that the B-theory is phenomenologically superior to the A-theory. Here $\mathrm{I}$ argue that it is.

We all know what we mean when we say that an event succeeded another, or that two events are simultaneous. Of course, our metaphysical understanding of these relations is an altogether different matter, but the meaning of these terms appears to be firmly grounded on our common experience of time. According to an influential view, we derive our mastery of these concepts directly from experience. Here is how Russell expressed it:

Immediate experience provides us with two time-relations among events: they may be simultaneous, or one may be earlier and the other later. These two are part of the crude data; it is not the case that only the events are given, and their time-order is added by our subjective activity. The time-order, within certain limits, is as much given as the events. ${ }^{5}$

3 Cf. D.C. Williams, 'The Myth of Passage', Fournal of Philosophy 48 (1951), 457-72.

4 Cf. S. Savitt, op. cit.

5 B. Russell, Our Knowledge of the External World (London: Allen and Unwin, 1914), 121-2. 
Following Dainton ${ }^{6}$ let us call the view that we directly perceive succession and simultaneity: phenomeno-temporal Realism, or Realism for short.

Prima facie, Realism does not commit one to the B-theory of time, nor does it favor it. Firstly, as I am understanding A-theories of time, these do not exclude that reality contains also independent and irreducible B-facts. ${ }^{7}$ If so, then the mere fact that we directly (and veridically) perceive B-relations is mute as to whether reality also contains irreducible A-facts, or as to whether we also perceive these.

Secondly, the view that we directly perceive temporal successions appears to be compatible with the view that we do so precisely by perceiving A-theoretic structures within individual acts of awareness. This is how so-called retentionalist views of temporal perception explain how we experience successions. According to Retentionalism, ${ }^{8}$ an experience of succession, like that of hearing Re following Do, consists of a momentary complex of experiential representations, comprising an immediate experience representing Re as present, together with a simultaneous experience (retention) representing Do as recently past.

Now, one may object to Retentionalism on the ground that it does not live up to careful phenomenological scrutiny. While hearing a rapid succession of notes, for example, it is not clear that we distinctly hear one of these as present, and others as past:

All the notes of a bar of a song seem to the listener to be contained in the present. All the changes of place of a meteor seem to the beholder to be contained in the present. At the instant of the termination of such series, no part of the time measured by them seems to be a past. ${ }^{9}$

Here, however, I do not wish to pursue this line of criticism. Rather than arguing that we $d o$ not (as a matter of contingent fact) perceive successions this way, I wish to argue that we could not. Let me stress since now that this does not entail that our experiences never represent such A-theoretic structures. From my argument, it only

6 B. Dainton, 'Temporal Consciousness', The Stanford Encyclopedia of Philosophy (Fall 2017 Edition), Edward N. Zalta (ed.).

7 Cf. L.R. Baker, The Metaphysics of Everyday Life (Cambridge: University Press, 2007).

8 Cf. E. Husserl, On the Phenomenology of Consciousness of Internal Time (trans. J.B. Brough. Dordrecht: Kluwer Academic Publishers, 1893-1917 [1991]).

E. R. Clay, quoted in W. James, Principles of Psychology (New York: Henry Holt, 1890 [1983]), 609. 


\section{Emiliano Boccardi}

follows that even if we sometimes did represent such structures in experience, it would not be these experiences which furnish our understanding with the empirical notion of temporal succession and dynamicity.

As I said, according to Retentionalism, we experience the temporal succession of say, Do and Re by representing Re as present and Do as (recently) past. This view has significant advantages for the A-theorist. Firstly, it makes room for the view that we directly experience dynamicity despite the fact that reality, and hence experience itself (being part of reality) is restricted to the present instant of time (Presentism).

Secondly, the view that experiences as of succession amount to experiences as of A-theoretic discriminations fits well with the contention, often made by A-theorists, that A-determinations (if real) provide the metaphysical ground for B-relations. This is why. McTaggart famously argued that, without A-theoretic distinctions, there could not be any genuinely temporal relations. A-theorists typically agree about this. Short of A-determinations (and their shifting from one event to the other), they think, whatever relations there might be which generate a linear order of events would fail to generate a genuine temporal order. ${ }^{10}$ McTaggart and the A-theorists conclude that it must be the - illusory, for McTaggart, and veridical for the A-theorists - experience of primitive A-determinations which produces the experience of temporal relations and dynamicity: if only A-determinations are capable of being dynamic, then only experiences of A-determinations can amount to experiences of dynamicity.

Accordingly, many A-theorists try to provide conceptual reductions of B-statements to (complexes of) A-statements: '[t]he Bseries is reducible to the A-series since B-relations can be analyzed in terms of A-determinations [...] The A-series is both necessary and it alone sufficient for accounting for all temporal facts'. ${ }^{11}$ This contention stems from the observation that temporal relations (B-relations), and hence the order that they induce on events, have an intrinsic sense. The notion of 'sense' at issue here is well expressed by Broad:

Three points on a line have an intrinsic order, i.e., $\mathrm{B}$ is between

$\mathrm{A}$ and $\mathrm{C}$, or $\mathrm{C}$ is between $\mathrm{B}$ and $\mathrm{A}$, or $\mathrm{A}$ is between $\mathrm{C}$ and $\mathrm{B}$.

10 Since he thought that shifting A-determinations cannot be real, he further argued that temporal relations must be unreal too (A-theorists of course disagree with this part of his argument).

11 R.M. Gale, The Language of Time (London: Routiedge \& Kegan. Paul, 1969), 86. 
This order is independent of any tacit reference to something transversing the line in a certain direction. By difference in sense I mean the sort of difference which there is between, say, $\mathrm{ABC}$ and CBA. Now points on a straight line do not have an intrinsic sense. ${ }^{12}$

Since A-theorists typically believe that only shifting A-determinations could provide a mere a-temporal ordering of events (a $\mathrm{C}$-series, in McTaggart terminology $)^{13}$ with an intrinsic sense, they conclude, with McTaggart, that A-determinations are conceptually fundamental. ${ }^{14}$

If this were true, it would follow that we could not directly experience B-relations if not by experiencing A-determinations, since we could not experience their intrinsic sense without experiencing A-theoretic properties. I shall argue that this cannot be the case. To do so, I shall I argue for the following theses:

1. First (section 2), that the fact that an event is present and another past is not, taken in isolation from other facts, a dynamical fact: it does not suffice, alone, to make reality dynamic. It follows that an experience as of an event being present and another past does not amount to an experience of dynamicity.

2. Second (section 2), that the logical conjunction of two or more incompatible A-theoretic structures similar to the one mentioned above is equally insufficient to make reality dynamic. It follows that an experience representing such juxtaposition of A-theoretic facts cannot amount to an experience of dynamicity.

3. I proceed (section 3) to argue that only the fact that there is a transition between the presentness of an event and the presentness of another event could constitute a dynamical fact. I provide an analysis of the notion of transition involved and conclude that it can only consist in a B-theoretic irreducible, intrinsically directed relation of succession between these

C.D. Broad, Scientific Thought (Routledge and Kegan Paul Ltd. London. Rpt. 1959, Littlefield, Adams \& Co., Patterson, New Jersey, 1923), 57.

13 According to McTaggart, the a-temporal C-series, ordered by the relation of 'inclusion', plays an essential role in explaining the illusion of time and dynamicity.

14 Cf. J.M.E. McTaggart, 'The Unreality of Time', Mind (1908) 18, $457-84,463-4$. 


\section{Emiliano Boccardi}

events (if such there be). It follows that only an experience as of such a succession could amount to an experience as of dynamicity.

4. Finally (section 4), I argue that the A-theoretic nature of the relata of such transitions does not contribute to make these facts dynamic: the B-theoretic relation of succession is alone necessary and sufficient to make a fact dynamic.

I conclude that the experience as of a B-theoretic transitions (regardless of whether these are transitions between A-theoretic facts or not) is alone necessary and sufficient for it being an experience of dynamicity.

In section 5, I consider two potential combatting maneuvers to salvage the alleged phenomenological superiority of the A-theory: abandoning Retentionalism and abandoning Realism. I argue that abandoning Retentionalism either amounts to conceding that the B-theory is phenomenologically superior to the A-theory, or faces the same problems discussed in section 2. The extreme maneuver of abandoning Realism, i.e. to claim that we never directly experience dynamic successions, finally, would equally deprive the A-theory of its chief allure: that of being uniquely capable of explaining our experience of dynamicity and temporal passage.

\section{The changelessness of A-determinations}

Let me start by pointing out a very common mistake. We often hear that the crucial point of contention between the A- and the B-theory is whether the A-or the $\mathrm{B}$-series is more fundamental. This conveys the mistaken impression that there could be a single A-series, ordering events from the distant to the near past, to the present, to the near and more distant future. This is surely wrong.

To see why it suffices to consider those A-theories which provide a conceptual reduction of presentness to features that are not essentially dynamic. Many Presentists, for example, think that presentness can be reduced to non-temporal concepts such as truth (Crisp 2007), ${ }^{15}$ actuality (Bigelow 1991), ${ }^{16}$ reality (Prior 1970), ${ }^{17}$ existence (Christensen

15 T. Crisp, 'Presentism and the grounding objection', Noûs 41.1 (2007), 90-109.

16 J. Bigelow, J. 'Worlds Enough for 'Time', Noûs 25 (1991), 1-19.

17 A. N. Prior, 'The Notion of the Present', Studium Generale 23 (1971), 245-48. 
1993), ${ }^{18}$ or being located at the 'edge' of a growing block (Broad 1923, Tooley 2997, Forrest 2004). ${ }^{19}$ Now, it is clear that the bases for the reduction of presentness that these accounts offer do not comprise essentially dynamic elements. Being true, or real, or actual, or being located at the last frontier of existence, in fact, are not essentially dynamic qualities, i.e. qualities that change by their own nature, just in virtue of being instantiated: something can well be true, or real, or actual, etc., without changing. It follows that these theories, unadorned, are not sufficient to provide us with an account of the passage of time.

Sure, most (if not all) A-theorists adorn their metaphysics by adding to the fact that a given time, $t$, is absolutely present, the fact that so many other times $t^{*}, \mathrm{t}^{* *}$, etc. have been and will be present too. Thus, for example, Skow claimed that "'The NOW is moving into the future" means (roughly) "The NOW is located at $t$, and it will be the case that the NOW is located at a time later than t"' ${ }^{20}$ This, it will be argued, surely suffices to make it true that time passes: if it is true that times other than the present have been and will be present too, then it must be also true that time passes, since if the present has reached and will reach different A-theoretic locations, this can only be because time passes. However, while this entailment may be correct, and even analytically correct at that, it does nothing to make individual A-series themselves dynamic in any sense.

The same point can be made in a number of different ways. Kit Fine, for example, made a similar point when he noted that ' $\mathrm{t}] \mathrm{he}$ passage of time requires that the moments of time be successively present and this appears to require more than the presentness of a single moment of time'. ${ }^{21}$ The A-theorist, Fine continues,

might appeal to the fact that any particular future time $\mathrm{t}^{+}$will be present and that any particular past time $\mathrm{t}^{-}$was present. However, the future presentness of $\mathrm{t}^{+}$amounts to no more than $t$ being present and $t^{+}$being later than $t$ and, similarly, the past presentness of $\mathrm{t}^{-}$amounts to no more than $\mathrm{t}$ being present and $\mathrm{t}^{-}$being earlier than $\mathrm{t}$. But then how can the

18 F. Christensen, Space-like Time (Toronto: University of Toronto Press, 1993).

19 C.D. Broad, op. cit.; M. Tooley, Time, Tense, and Causation (Oxford University Press, 1997); P. Forrest, 'The real but dead past: a reply to Braddon-Mitchell', Analysis 64 (2004), 358-62.

20 B. Skow, 'Why does Time Pass?', Nous 46 (2012), 223-242, 224.

21 K. Fine, 'Tense and Reality', in Modality and Tense: Philosophical Papers (ed.) K. Fine (Oxford University Press, 2005), 261-320, 287 (emphasis added). 


\section{Emiliano Boccardi}

passage of time be seen to rest on the fact that a given time is present and that various other times are either earlier or later than that time?22

We are now in the position to see what's wrong with the retentionalist version of Realism. If we do directly experience Do being followed by Re (i.e. if Realism is true), then surely we don't experience this as a sequence going from Do being past to Re being present: this is absurd. Re being past and Do being present - supposedly represented simultaneously within a single act of awareness - are simultaneous states of affairs, hence a fortiori a representation of them cannot amount to a representation of any change. If there are A-theoretic successions at all, these are from, say, Do being present to Re being present, not from Do being past to Re being present. As Huw Price put it: '[the notions of passage, change or temporal transition] seem to involve a relation between equals, a passing of the baton between one state of affairs an another'. ${ }^{23}$

\section{Only primitive B-theoretic successions could be dynamic.}

We are tricked into thinking that tense properties are immune from the charge of changelessness because we tend to read more into the contention that there are past states of affairs than it actually conveys. We assume that if something is (already) past it must have become past first. While this assumption may be correct, however, the proposition that an event $i s$ past does still not convey the same thought as the proposition that that event was becoming past, when (or before) it became past.

To illustrate this difficulty, consider Thomas Crisp's proposal to reduce the notion of presentness to the truth of one (unique) element of a series of abstract ('ersatz') times, construed as maximally consistent sets of propositions (abstract representations of an instantaneous state of the world). The elusive, impermanent aspect of time, according to this view, is nothing over and above the logical conjunction of a thing's former existence with its current non-existence. Caesar did exist, for example, and he doesn't any more. The presentness of Caesar's existence, during his life, was nothing over and above

22 K. Fine, op. cit. note 21 See also my 'If it ain't Moving it shall not be Moved', Topoi 34.1 (2015), 171-185, for an extensive discussion of this defect of comparative accounts of passage.

${ }_{23}$ H. Price, 'The Flow of Time', in The Oxford Handbook of Time (ed.) Craig Callender (Oxford University Press, 2011), 279. 
the truth of the proposition that he (tenselessly) exists. Likewise, the presentness of his current non-existence is nothing more than the truth of the proposition that he doesn't exist. As Oaklander has pointed out in criticizing this comparative account of passage, however:

since on Crisp's view all times are present at the time they are regardless of what time it is, there is no basis or ground in the ersatz $\mathrm{B}$-series for picking out one and only one time that has the property of being present to the exclusion of all earlier and later times that are (tenselessly) also present at their own respective time $[\ldots] \cdot{ }^{24}$

The disregard of A-theorists for the fact of transiency is particularly clear in Crisp's response to Oaklander:

Imagine someone trying to argue against actualism in the same vein. Actualists, they say, hold that one and only one world W1 has the property being actual but that for some distinct world W2 logically accessible from W1, POSS[W2 has being actual]. But this won't do, says our objector, because if W1 has being actual and POSS[W2 has being actual], then, contrary to actualism, both W1 and W2 have being actual. This isn't an impressive objection to actualism. But is it interestingly different than objecting to presentism by claiming that if (*) is true, then every abstract time has each of the A-properties?25

It is interestingly different, I argue! It is, at least, if one wishes to incorporate the idea that which states of affairs happen to be present is a matter that keeps changing. Possible worlds, unlike times (which must become past), are not required to become real, and the actual world is not required to become merely possible. That's why that argument is unimpressive.

Indeed, M. J. Cresswell proposed a modal version of Mc'Taggart's argument, very much in line with that which Crisp has ridiculed. It was devised to show that primitive modality is unreal, just like McTaggart tried to show that time is unreal. Here is how it goes:

Many M-positions are incompatible with each other. An event which is merely possible for example cannot also be actual.

24 N. Oaklander, 'Mc'Taggart's Paradox and Crisp's Presentism', Philosophia 38 (2010), 229-241, 236.

25 T. Crisp, 'Review of L. Nathan Oaklander's The Ontology of Time', Notre Dame Philosophical Reviews: http://ndpr.nd.edu/review.cfm?id=2201 (2005), my emphasis. 


\section{Emiliano Boccardi}

Being merely possible and being actual are mutually incompatible properties of things and events. But because they are contingencies everything has to have them all. Everything occupies every M-position from merely possible to actual. But nothing can really have incompatible properties, so nothing in reality has modal properties. M-positions are a myth. ${ }^{26}$

This line of argument is appropriate to expose the essential role of the transitory aspect of time in Mc'Taggart's reasoning. As Heather Dyke has rightly observed:

In seeking to construct a modal analogue of Mc'Taggart's paradox, Cresswell faltered when it came to invoking a modal analogue of the continual change of tense that events undergo. He appealed to the 'contingency' of modal properties, but it clearly does not validate the analogous modal inference. Thus, this modal analogue of Mc'Taggart's paradox fails to force one into the position either of rejecting modality as incoherent (as Mc'Taggart rejects tense as incoherent) or of adopting modal realism (as Mellor adopts tenseless time). It fails, I believe, because there is no clear modal analogue of the change of tense that events and times appear to undergo. ${ }^{27}$

It follows that, if the A-theory is true, then temporal reality does not consist of one individual A-series, but of a series of such series. This point, largely neglected in the literature, was noted by Gale when he claimed that '[b]ecoming requires that there be a sequence of Aseries, i.e., that events change with respect to their A-determinations'. ${ }^{28}$ In our example, temporal reality consists of two A-series: one, $A_{1}$, in which Do is present and Re future, and the other, $A_{2}$ in which Do is past and Re present. Neither series alone could turn an a-temporal ordering of events (a C-series) into a genuine $\mathrm{B}$-series since, as noted by Nathan Oaklander, 'there is nothing in a single A-series superimposed on a $\mathrm{C}$-series that changes. There is nothing

26 M. J. Cresswell, 'Modality and Mellor's McTaggart', Stud. Logica 49 (1990), 163-170, 165-6.

27 H. Dyke, 'Real times and possible worlds', in Questions of Time and Tense (ed.) Robin le Poidevin (Oxford University Press, 1998), 93-117, 103.

28 R. Gale, op. cit., 190. This possibility has also been contemplated and criticized in N. Oaklander, 'Mctaggart's Paradox Defended', Metaphysica 3 (1), 2002, 16: '[p]erhaps an A-theorist could construe temporal becoming as involving a second series whose terms are each an $A_{1}$-series (of the first level). [...] However, there is no way that can be consistently done.' 
that has a property and then loses it'. ${ }^{29}$ This leaves the A-theorist with the following dilemma.

The crucial question to be asked about the series of A-series is: what relation is there between these various $\mathrm{A}_{\mathrm{i}}$-series? Such relation is either temporal or non-temporal. I argue that both of these options have unwanted consequence for the claim that the A-theory is capable of doing justice to our experience of time (let alone for the claim that it is uniquely so capable).

If the relation is non-temporal, e.g. if the passage of time consists of a $\mathrm{C}$-series of $\mathrm{A}$-series, then each term in both $\mathrm{A}_{1}$ and $\mathrm{A}_{2}$, say Do, has (timelessly) both incompatible A-determinations: past and present. It cannot, in fact, be claimed that these are had successively.

If, instead, it is temporal, i.e. if $\mathrm{A}_{1}$ was temporally succeeded by $\mathrm{A}_{2}$, then it could only consist of an irreducible B-relation. In fact, to claim that this relation of succession, that between $A_{1}$ and $A_{2}$, stands in further need of another $\mathrm{A}$-series to acquire its intrinsic sense, and hence to count as a genuine B-relation, would inevitably launch us into a vicious regress. By now, McTaggart's alarm bells should be firing all over the place.

\section{The representation of A-determinations cannot contribute to represent dynamic features of reality.}

The A-theorist might hope to block this conclusion by claiming that the entire series of A-series is somehow 'contained' analytically within each of its terms. Consider for example how Richard Gale expresses the relation between the various A-series:

Becoming requires that there be a sequence of $\mathrm{A}$-series, i.e., that events change with respect to their A-determinations. How can this series of A-series be derived from a single A-series? It can easily be shown that if there is one A-series there must be a series of A-series. Assume that the A-series consists of events M, N and

N. Oaklander, op. cit. ibid. It might be objected that the A-series as it was introduced by McTaggart is a series of positions in time, considered in abstraction from any contents. Since the ordering induced by A-determinations on these abstract positions is blind to the continuous shifting of the present, in this sense there is only one A-series. Here, however, we are concerned with a notion of 'A-series' the encounter with which would account for our experience of change and dynamicity. This, I have argued, can only consist of a series of different concrete A-series (thanks to an anonymous referee for pointing this out to me). 


\section{Emiliano Boccardi}

$\mathrm{O}$, which are respectively past, present and future. A past (future) event by definition is one which was (will be) present, therefore, there was (will be) an A-series in which $\mathrm{M}(\mathrm{O})$ is present. Thus, if there is one A-series there is becoming - a 'series of A-series'; and if the A-series is objective so too is becoming. ${ }^{30}$

Now, while it may be conceded that if there were one objective Aseries, there would have to be an entire series of A-series, and that if this were the case, temporal becoming would be objective too, this order of implication obscures the real order of explanation. I have argued, in fact, that if it wasn't for genuine and irreducible B-relations between incompatible A-series, there would be no becoming or dynamicity. But if there was no becoming, there wouldn't be even a single A-series to start with. In other words, I have argued that, without irreducible B-relations, each wannabe $\mathrm{A}$-series would be a mere $\mathrm{C}$-series: no event could be objectively past if time didn't pass; and I have also argued that time wouldn't pass without irreducible B-relations. Therefore, no experience could represent genuine tense determinations without representing irreducible B-relations between them.

Since it is impossible that we ever experience transparent contradictions (e.g. Do being tenselessly both past and present), if the A-theorist wants to uphold Realism, i.e. if she wants to claim that we directly experience successions and dynamicity, she will have to concede that a necessary ingredient of these is our experiencing irreducible B-relations. Moreover, since our further representing the terms of these relations as objectively present (if we ever do this at all) would do nothing to contribute to the dynamicity of these contents (see Section 2 above), she will have to further concede that representing such irreducible B-relations is also sufficient for our experience of dynamicity.

Summing up, I have argued that Realism is incompatible with the A-theory of time. In a nutshell, my argument was that, if one wants to uphold Realism, one must concede that the direct experience of B-relations is necessary and sufficient for the direct experience of dynamicity, thus fatally damaging the main allure of the A-theory, i.e. its alleged phenomenological superiority over the B-theory.

\section{Where does this leave the A-theory?}

Let me conclude by mentioning two ways in which the A-theorist might respond to my argument. I shall argue that they both fail. In

$30 \quad$ R. Gale, op. cit., 190. 
deriving the conclusion that Realism is incompatible with the A-theory, I have so far discussed the shortcomings of Retentionalism. It will be immediately objected that (1) endorsing Realism does not commit the A-theorist to Retentionalism; and that (2) endorsing an A-theory of time does not commit one to Realism. In the rest of this paper I shall argue that neither response can be used to salvage the presumed phenomenological superiority of the A-theory.

There are two ways in which the A-theorist may try to uphold Realism while denying Retentionalism. First, while continuing to endorse an atomistic view of temporal experience, according to which we apprehend dynamicity within momentary (atomic) acts of awareness, she might deny that the internal structure of the contents of such experiences comprises tense differentiations. Lee advocates a (rare) example of such a view:

The content of an atomic experience need not divide events into past, present and future, as we find in Husserl's (1964) position, which involves the well-known distinction between 'retention' 'perception' and 'protention' [...]. Atomic theorists could deny that there is any tensing in the content of experience at all. Or they could hold that everything that is perceived seems to be happening roughly in the present, in a way that is consistent with the relevant events being non-simultaneous, but that no further differentiation of tense is involved. ${ }^{31}$

Here I do not wish to discuss the value of this view as a phenomenological theory. For my purposes, it suffices to point out that it amounts to a concession that experiences representing irreducible B-relations are necessary and sufficient for representing dynamic contents.

The second way in which the A-theorist might uphold Realism while denying Retentionalism, is by endorsing a non-atomic, Extentionalist view of time perception, according to which dynamic experiences are themselves extended through time. Now, one may reasonably claim that this view is simply incompatible with most standard versions of the A-theory (e.g. with Presentism), on the grounds that, "[i]f the momentary present is all that is real, there is no obvious option but to locate our experience of change and persistence in the momentary present.' ${ }^{32}$ But even if one were to abandon Presentism in favor of an A-theory which does not restrict what is

31 G. Lee, 'Temporal Experience and the Temporal Structure of Experience', Philos Impr. 14(1) 2014, 1-21.

32 B. Dainton, op. cit. 


\section{Emiliano Boccardi}

real to the momentary present, the same criticism that was raised against Retentionalism would apply here too. This is why.

Consider for example the Growing Block view, ${ }^{33}$ according to which reality consists of all the events that happened up to the present time, including those that are happening now. The passage of time consists in the fact that more of reality comes to be as time goes by. Presentness is conceptually reduced to 'reality at the edge of existence'. Could the Realist growing blocker claim that experiences as of dynamicity extend from the present back to the past for a short stretch of time? No, I argue. As I have already said, dynamic successions do not relate past events with present events, they relate present events with (successive) present events, which within a growing block view of time amounts to relating different phases of the growing block, rather than different events within a single block as it is at any given time.

Again, the A-theorist faces the same dilemma as the Retentionalist. What is the relation between these phases? If it is non-temporal, for example if it amounts to an internal relation between the different sizes of the relata, then a contradiction ensues (the block would tenselessly have incompatible sizes). On the other hand, if $i t i s$ temporal, it can only be an irreducible relation of succession, which alone could ground the truth that events that are not at the edge of existence are objectively past. Once again, the perception of pure B-relations would turn out to be necessary for our experiences of dynamicity. Moreover, since the perception of events as present (i.e. being located at the latest end of the block), if such there be, would do nothing to contribute to the dynamicity of the content perceived, the perception of pure B-relations would turn out to be also sufficient for our experiences of dynamicity.

Finally, the A-theorist could abandon Realism altogether. This is how Thomas Reid famously expressed this Anti-Realist view:

It may here be observed that, if we speak strictly and philosophically, no kind of succession can be an object either of the senses or of consciousness; because the operations of both are confined to the present point of time, and there can be no succession in a point of time; and on that account the motion of a body, which is a successive change of place, could not be observed by the senses alone without the aid of memory. ${ }^{34}$

33 Cf. C.D. Broad, op. cit; M. Tooley, op. cit.; P. Forrest, op. cit.

34 T. Reid, Essays on the Intellectual Powers of Man, (ed.) D.R. Brookes (Knud, Penn State Press, 1786 [2002]), Essay III, chapter V. 
This view, though phenomenologically dubious, has the advantage (for the A-theorist) that it preserves the idea that dynamicity requires tense distinctions while being compatible with Presentism. Unfortunately, however, it falls prey to the same difficulties that we discussed in the case of Retentionalism. What dynamicity can there be in the mere simultaneous contrast between a perceived content and a remembered one? As I have argued at length, such representations of solitary A-structures do not represent any dynamicity, regardless of whether these representations are perceptual (as Realism claims) or not. Why should we associate the (present) contrast between an experienced event and a remembered one with something dynamic?

Again, surely the concept of past contains analytically the notion of passage (it is perhaps more than a coincidence that 'past' used to be the past tense of 'to pass'). But whence should we get the information that memories of events represent past events in this robust sense, if not from the perception, or pure intuition, that these events have dynamically become past, i.e. that there was a dynamic (B-theoretic) succession between their being present and the presently perceived events being present? Perhaps Wittgenstein had this question in mind when he asked:

If memory is no kind of seeing into the past, how do we know at all that it is to be taken as referring to the past? We could then remember some incident and be in doubt whether in our memory image we have a picture of the past or of the future. We can of course say: I do not see the past, only a picture of the past. But how do I know it's a picture of the past [...]? Have we, say, learnt from experience to interpret these pictures as pictures of the past? ${ }^{35}$

\section{Conclusions}

I have argued that both Realism and Anti-Realism are incompatible with the claimed phenomenological superiority of the A-theory of time. The experience of time's dynamicity cannot be accounted for solely in terms of representations of irreducible A-determinations, because any representation which is adequate to ground the experience of time's dynamicity must itself involve representation of irreducible B-relations, while it needs not involve representation of A-determinations. Even if, as a matter of contingent fact, our

35

L. Wittgenstein, 'Philosophical Remarks', in The Wittgenstein Reader (ed.) A. Kenny (Oxford, Wiley Blackwell, 1975 [2005]), 82. 


\section{Emiliano Boccardi}

experiences of dynamicity consisted of representations of successions of incompatible A-theoretic orderings, what would account for them being experiences of dynamicity would be solely the B-theoretic relation of succession, rather than the irrelevant A-theoretic nature of the relata.

There is a structural similarity between the arguments advanced here and Mc'Taggart's argument for the fundamentality of the A-series. Mc'Taggart derived the (phenomenological) conclusion that an experience as of an irreducible B-relation holding between two events cannot amount to an experience of change, from the (metaphysical) observation that B-relations are unchanging ('permanent'). My argument, likewise, derived the (phenomenological) conclusion that an experience as of a logical conjunction of irreducible A-theoretic facts cannot amount to an experience of dynamicity, from the (metaphysical) observation that the represented facts amount to a mere static juxtaposition of non-dynamic states of affairs.

This turns the tables on McTaggart as far as which series, the A- or the B-series, is fundamental, but it needs not contradict his radical conclusion as to the unreality of time. The arguments I have offered do not show that time is real, nor do they impeach Mc'Taggart's reasons for denying that B-relations are static. What they do show is that if the wannabe A-theorist were to insist, on metaphysical grounds like Mc'Taggart did, that primitive B-relations could not be intrinsically directed or dynamic in any way, then she will have to agree with McTaggart that time is unreal. Those who so deny that reality is dynamic, however, as I have argued in my The Delusive Illusion of Passage, ${ }^{36}$ must also further deny (contrary to Mc'Taggart) that it appears to be dynamic. This makes this option even less palatable than it is sometimes believed to be.

In a nutshell, I have argued that if, on the one hand, the A-theorist wants to uphold Realism, she must concede that the direct experience of irreducible B-relations is necessary and sufficient for the direct experience of dynamicity. On the other hand, if she abandons Realism, she fatally damages the main allure of her theory, i.e. its alleged phenomenological superiority over the B-theory.

EMILIANO BOCCARDI (emiliano.boccardi@gmail.com) is postdoctoral associate in the Center for Logic, Epistemology and History of Science of the State University of Campinas. His recent publications include 'Time as Motion' (Metaphysica, 2018), 'The Delusive Illusion of Passage' (with F. Perelda, Analysis, 2017) and 'If it ain't Moving it shall not be Moved' ('Topoi, 2015). He guest-edited the special issues Time and Reality I and II (Manuscrito, 2016-17).

36 E. Boccardi and F. Perelda, 'The Delusive Illusion of Passage', Analysis, anx128. https://doi.org/10.1093/analys/anx128, 2017. 